\title{
REVIEW
}

\section{Food fortification for bone health in adulthood: a scoping review}

\author{
SJ Whiting ${ }^{1}$, WM Kohrt ${ }^{2}$, MP Warren ${ }^{3}$, MI Kraenzlin ${ }^{4}$ and J-P Bonjour ${ }^{5}$
}

Food fortification can deliver essential micronutrients to large population segments without modifications in consumption pattern, suggesting that fortified foods may be formulated for populations at risk for fragility fractures. This scoping review determined the extent to which randomized controlled studies have been carried out to test the impact of fortified foods on bone outcomes, searching PubMed for all studies using the terms 'fortified AND bone', and 'fortification AND bone'. Studies were restricted to English language, published between 1996 and June 2015. From 360 articles, 24 studies met the following criteria: human study in adults $\geqslant 18$ years (excluding pregnancy or lactation); original study of a fortified food over time, with specific bone outcomes measured pre- and post intervention. Six studies involved adults $<50$ years; 18 involved adults $\geqslant 50$ years. Singly or in combination, 17 studies included calcium and 16 included vitamin D. There were 1 or 2 studies involving either vitamin $\mathrm{K}$, magnesium, iron, zinc, B-vitamins, inulin or isoflavones. For adults $<50$ years, the four studies involving calcium or vitamin $\mathrm{D}$ showed a beneficial effect on bone remodeling. For adults $\geqslant 50$ years, $n=14$ provided calcium and/or vitamin $D$, and there was a significant bone turnover reduction. No consistent effects were reported in studies in which addition of vitamin K, folic acid or isoflavone was assessed. Results from this scoping review indicate that up to now most studies of fortification with bone health have evaluated calcium and/or vitamin $D$ and that these nutrients show beneficial effects on bone remodeling.

European Journal of Clinical Nutrition (2016) 70, 1099-1105; doi:10.1038/ejcn.2016.42; published online 30 March 2016

\section{INTRODUCTION}

Over the last two decades, the impact of nutrition on bone health has been extensively considered, and various diets, foods and nutrients have been studied for their potential effects on bone. ${ }^{1,2}$ The relation between dairy food products and bone acquisition, as well as maintenance, has been the object of several reports. ${ }^{3-9}$ The impact on bone health of animal and/or plant protein macronutrients has been a prominent topic in various reports (see for review ref. 10). Among micronutrients, calcium and vitamin $D$ are the two elements that were most frequently studied in randomized controlled trials involving supplements and their effects on various bone outcomes, including fragility fractures. ${ }^{11-15}$ The role of other micronutrients, vitamin $\mathrm{K}$, magnesium, phosphorus and strontium, has also been evaluated in regard to calcium economy, bone metabolism and resistance to mechanical loading (see for review ref. 16). The effects of potassium and bicarbonate in relation to acid-base balance and bone health have been the subject of several reports. ${ }^{17-21}$ Other nutrients such as manganese, zinc, iron, isoflavones and soluble fibers have received some attention as to their effects on bone. ${ }^{22-24}$ Most of the evidence is from studies of supplemental micronutrients. ${ }^{25}$ The European Food Safety Authority has published positive opinions for making a claim that vitamin $\mathrm{K}^{26}$ magnesium, ${ }^{27}$ phosphorus, ${ }^{28}$ manganese ${ }^{29}$ and zinc ${ }^{30}$ are beneficial to the general population (Table 1). Presently European Food Safety Authority allows fortification only with those micronutrients that are inadequate in the European diet, that is, only for vitamin $\mathrm{K}^{26}$ and magnesium. ${ }^{27}$ However, few actual fortification studies have been carried out with these two micronutrients.

\section{FOOD FORTIFICATION: DEFINITION AND GENERAL AIMS}

Food fortification is the process of adding micronutrients to foods. As defined by the World Health Organization (WHO) and the Food and Agricultural Organization of the United Nations, fortification refers to 'the practice of deliberately increasing the content of an essential micronutrient, that is, vitamins or minerals in a food, irrespective of whether the nutrients were originally in the food before processing or not, so as to provide a health benefit with minimal risk to health' ${ }^{\prime 31}$ Certain types of fortification are more accurately called enrichment in which micronutrients added to food are those that are lost during processing. ${ }^{31}$ Micronutrient malnutrition is frequent and severe in the developing world; nevertheless, it can also represent a public health problem in more industrialized countries. ${ }^{32}$ Food fortification has the advantage of delivering essential nutrients to large segments of the population without requiring radical changes in food consumption patterns. ${ }^{32}$ Foods used as fortification vehicles vary from country to country, but they generally include cereals and cereal-based products, milk and dairy products, fats and oils, tea and other beverages, and various condiments such as salt, soy sauce and sugar. In practice, the choice of any combination

\footnotetext{
${ }^{1}$ College of Pharmacy and Nutrition, University of Saskatchewan, Saskatoon, SK, Canada; ${ }^{2}$ Department of Medicine, Division of Geriatric Medicine, University of Colorado, Denver, CO, USA; ${ }^{3}$ Department of Obstetrics and Gynecology and Medicine, Columbia University Medical Center, New York, NY, USA; ${ }^{4}$ Department of Medicine, Division of Endocrinology, Diabetes and Metabolism, University Hospital, Bale, Switzerland and ${ }^{5}$ Department of Internal Medicine Specialties, Division of Bone Disease, University Hospitals and Faculty of Medicine, Geneva, Switzerland. Correspondence: Professor J-P Bonjour, Department of Internal Medicine Specialties, Division of Bone Diseases Geneva University Hospitals and Faculty of Medicine, Rue Gabrielle Perret-Gentil 4, Geneva CH-1211 Geneva 14, Switzerland.
}

E-mail: jean-philippe.bonjour@unige.ch

Received 30 October 2015; revised 14 February 2016; accepted 18 February 2016; published online 30 March 2016 
of food vehicle and fortificant is mainly governed by both technological and regulatory factors. ${ }^{31,32}$

\section{IMPORTANCE OF FOOD FORTIFICATION FOR REDUCING RISK OF BONE FRAGILITY}

Bone is a living tissue, and as such all essential nutrients are needed to maintain bone integrity throughout the life cycle. When dietary intakes do not meet needs, nutrient gaps can be filled by means of supplementation and/or fortification. Many studies on the relationship between diet and bone involve supplements because their use facilitates the setting up of randomized clinical trials that compare tablets containing or not the active ingredient. However, dietary surveys in industrialized countries indicate that the prevalence of supplement use in the population can considerably vary, from $40-53 \%$ in the USA and Canada ${ }^{33,34}$ to 9.3-26\% in Europe. ${ }^{35,36}$ A recent systematic review has assessed the efficacy of various micronutrients on bone health in older adults by selecting and summarizing six studies involving supplements, namely calcium with or without vitamin $D$ and vitamin $\mathrm{K}^{25}$ However, in this systematic review of randomized controlled trials, ${ }^{25}$ there is no mention of fortification studies involving these and other micronutrients deemed beneficial to bone. Therefore, it is of interest to determine the impact of food fortification on bone in adulthood, with particular emphasis in postmenopausal women and older adults.

\section{SCOPING REVIEW METHODOLOGY}

As assessment of potential size and scope of available literature, we have conducted a scoping review with the aim of determining to what extent studies aimed at measuring the effects of fortified foods on bone have been carried out. ${ }^{37}$ We searched PubMed for all studies using the terms 'fortified' AND 'bone', and 'fortification' AND 'bone'. Studies were restricted to those in the English language published between January 1996 and 30 June 2015. For the former search terms, 360 articles were found, and for the latter a further 6 articles were found. First the title, and then the abstract of each listed article was examined and only those with the following inclusion criteria were retained: human study, original study (not review), study involving comparison of a fortified food over time (not cross-sectional) when time was superior to 1 week, specific bone measurement such as bone turnover markers and/or bone mineral density, study of adults (not infants, children, adolescents, pregnancy or lactation). There were 32 distinct publications that fit the inclusion criteria. However, several articles reporting on the same cohort were published more than once. When this occurred, we grouped the articles as a single study listing all citations. Studies are grouped according to age: Table 2 for studies on young adults up to approximately age 50 years and Table 3 for studies of older adults including postmenopausal women. There were six original distinct studies on fortified foods and bone involving young adults, and 18 involving older adults (Figure 1).

\section{FORTIFICATION STUDIES OF YOUNG ADULTS ( $<50$ YEARS)}

For young adults, out of the six studies found, three involved fortifying a dairy food: $:^{38-40}$ one with inulin; ${ }^{41}$ two with iron; ${ }^{40,42}$ three with calcium; ${ }^{38,39,43}$ and two with vitamin D. ${ }^{40,43}$ Results are summarized in Table 2 . The effects were not conclusive, but there is some indication that additional calcium or vitamin $D^{38-40}$ reduced biochemical markers of bone turnover, particularly showing decreases in those markers (CTX, NTX) that reflect the bone resorption rate (Table 2 ).

\section{FORTIFICATION STUDIES OF OLDER ADULTS (POSTMENOPAUSAL WOMEN AND MEN $\geqslant 50$ YEARS)}

There were three times more studies with adults over 50 years than below. These studies ${ }^{39,44-67}$ involved many combinations of nutrients added to foods (Table 3 ). Most studies (16 of 18) involved fortification of milk or other dairy products. In 12 studies, both vitamin $D$ and calcium were added and in 4 trials either calcium or vitamin D (Figure 1). In these 16 studies, results were consistent in showing a reduced bone turnover with evidence of improved bone density and/or strength (Table 3). Other nutrients added to foods included magnesium, vitamin $\mathrm{K}$, folic acid and isoflavones, but there were not enough replicates to provide conclusive results.

A potential concern in examining fortification studies of older adults was that several trials used only a single-arm design. However, the treatment of these single-arm design studies gave similar results-improvement in bone outcomes with vitamin D and/or calcium - to the treatment arms of the two-arm design studies (Table 3). In other studies, the fortified foods were not compared with unfortified equivalent foods. In most cases, these studies provided evidence that a fortified dairy product was efficacious in improving bone outcomes but did not provide evidence that the beneficial response was due to the specific nutrients that were added to the dairy food.

\section{FOOD VEHICLES FOR FORTIFICATION}

As described above, dairy was often used as the food that was fortified in the studies we found (Table 2; Table 3). Taking into

Table 1. EFSA positive opinions on vitamins and minerals other than calcium and vitamin $D$ for making a bone health claim for the general population

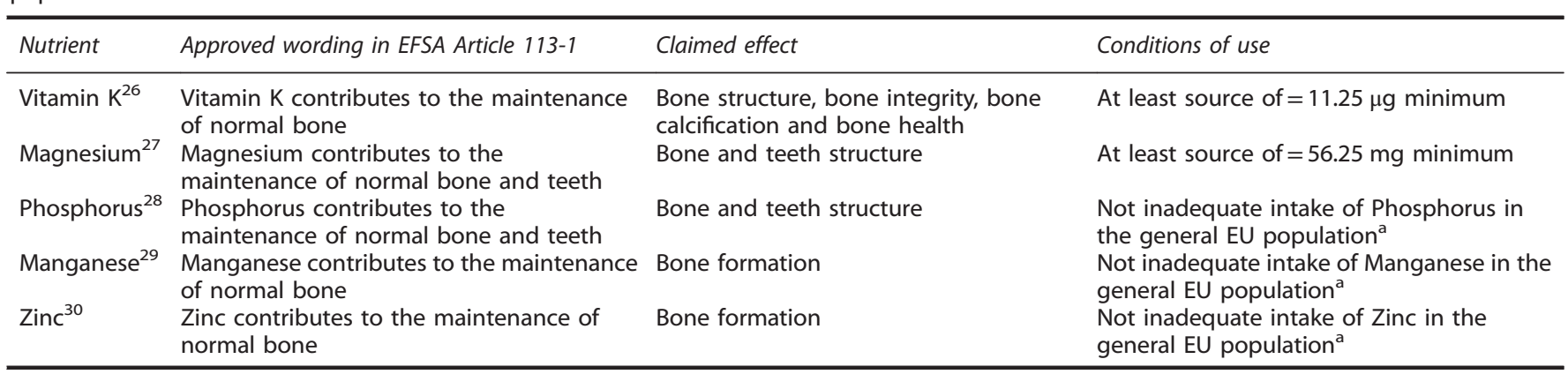

Abbreviations: EFSA, European Food Safety Authority; EU, European Union. Table content drawn from references 26 to 30 . Table content drawn from

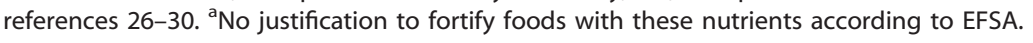




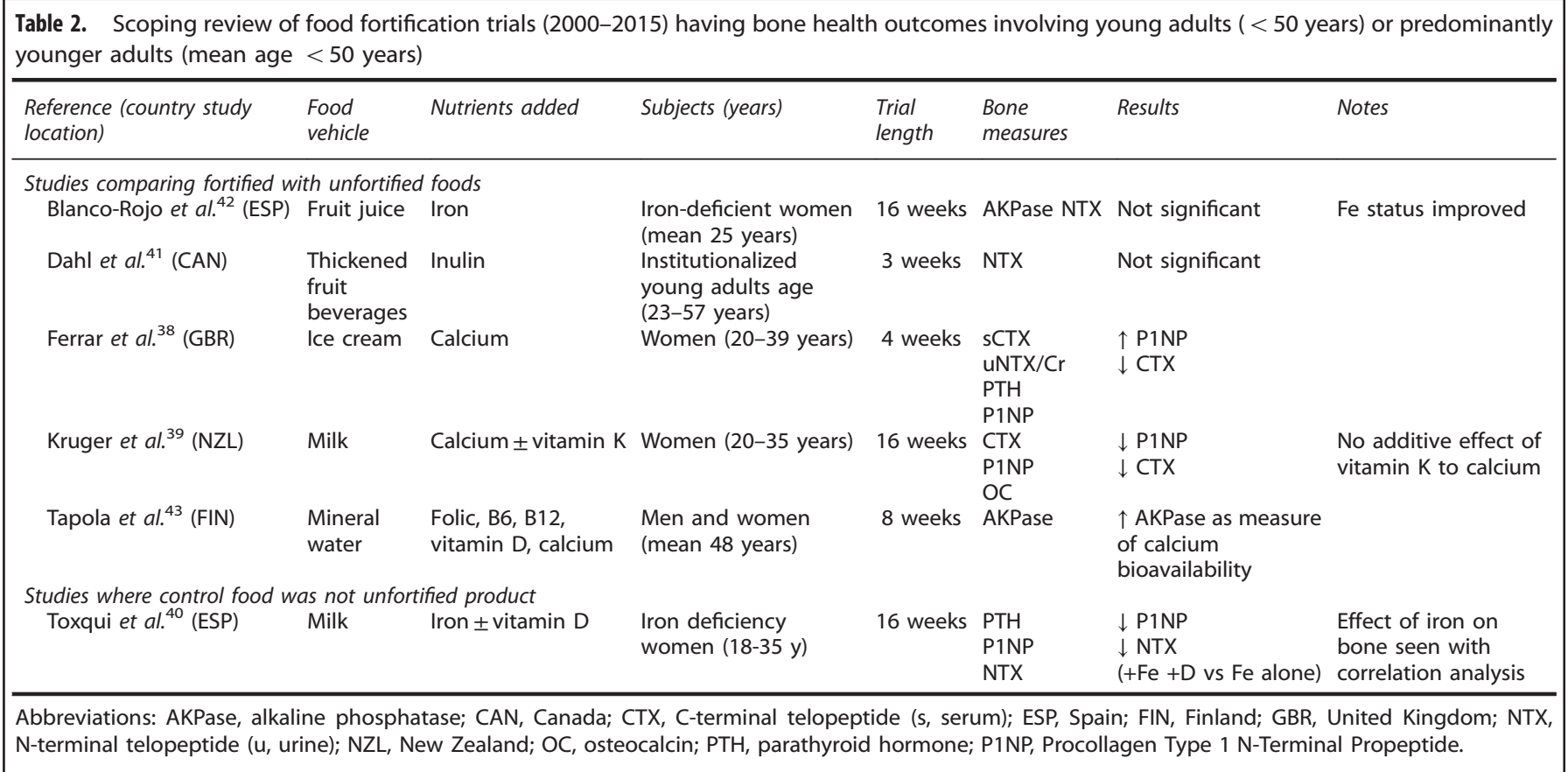

account that both dietary calcium and proteins can exert positive and possibly synergistic effects in the preservation of bone integrity (see for review ref. 68), dairy is a food of interest as they contain these two nutrients in appreciable amounts, as compared with their recommended daily allowance, and can especially be useful for older adults who have low appetite and therefore are less likely to choose more than one serving of a dairy product per day. In contrast, the natural vitamin $D$ content in dairy is far too low to be sufficient to meet the body needs, especially in countries such as Australia, France and the UK where mandatory vitamin D fortification is not practiced. In most usual western diets, unfortified foods other than dairy do not provide a sufficient supply of vitamin D to compensate for an inadequate year-round solar UVB exposure.

The fortification of milk and/or other dairy products with calcium is warranted for subjects whose daily portion size is insufficient to meet the recommended dietary allowance values as estimated by the Institute of Medicine and other national or international food agencies. ${ }^{1,69,70}$ A first considered situation was that of the low-birth weight infant fed either human milk or commercial formula that both contain insufficient quantities of calcium and phosphate. ${ }^{71,72}$ Besides this very early life critical period, there are other situations when the calcium balance resulting from the usual food consumption is too low to secure the optimal needs for bone. This can be the case during childhood and adolescence to cope with the enhanced bone accrual or in postmenopausal women and elderly to prevent the accelerated bone loss. In these two physiological situations, consumption of fortified dairy products appears to be particularly appropriate for subjects who, deliberately or not, choose to limit their energy intake and ingest just one dairy serving per day.

\section{BIOCHEMICAL MARKERS TO ASSESS FORTIFIED FOOD EFFECTS ON BONE}

The main observation drawn from this scoping review is that, in the majority of the 24 trials, fortified dairy foods improved bone through reduced bone turnover. This assessment corroborates the importance of measuring circulating factors reflecting bone remodeling to test the effects of fortified foods. As recently reviewed, clinical trials aimed at testing nutritional products on bone outcomes need to use surrogate end points for assessing anti-fracture efficacy. ${ }^{73}$ Fragility fracture-related measurements include specific hormonal factors (PTH, IGF-l; see for reviews refs 74,75$)$ and bone turnover markers related either to bone formation (for example, P1NP, osteocalcin, alkaline phosphatase) or to bone resorption (for example, NTX, CTX, TRAP5b; see for reviews refs 76-78). Measurement of turnover markers within a few weeks or months after the onset of an intervention can predict the future rate of bone loss and in the long term the risk of fragility fracture. ${ }^{79-81}$ This prediction lies on a fundamental mechanism of bone biology: modification in remodeling is the key process on which both pharmaceutical agents and nutrients exert their anti-catabolic or anabolic action on bone structural integrity and resistance to mechanical loading. ${ }^{82}$

In fact, use of bone turnover markers is critical to carry out food fortification studies that can be expensive because of food preparation and distribution costs, comparatively with studies testing the effects of nutrient supplements. ${ }^{73}$ Figure 2 illustrates that, in two independent randomized controlled trials conducted in older women, there were significantly greater effects of calcium and vitamin D-fortified yogurts vs unfortified equivalent yogurts on serum 25OHD and PTH. Furthermore, TRAP5b, a specific bone resorption marker, was consistently reduced in the two trials.

\section{SAFETY CONSIDERATIONS}

As expressed by food regulatory agencies, replacement of nutrient losses during food processing and correction of established deficiencies should guide enrichment and fortification policy, respectively (see for reviews refs 32,83 ). As mentioned above, calcium and vitamin D are the two main fortificants used to improve bone health. For both micronutrients, the safety margin can be considered as relatively wide. According to the 2011 report from the Institute of Medicine (IOM), the tolerable upper levels for adults are considered to be $2000-2500 \mathrm{mg} / \mathrm{d}$ and $4000 \mathrm{U} / \mathrm{d}$ $(100 \mu \mathrm{g} / \mathrm{d})$ for calcium and vitamin $\mathrm{D}$, respectively. ${ }^{70}$ Above these levels, there is a risk of adverse events such as the occurrence of hypercalcemia, hypercalciuria, nephrolithiasis, vascular and soft tissue calcification and for vitamin $D$ even an 


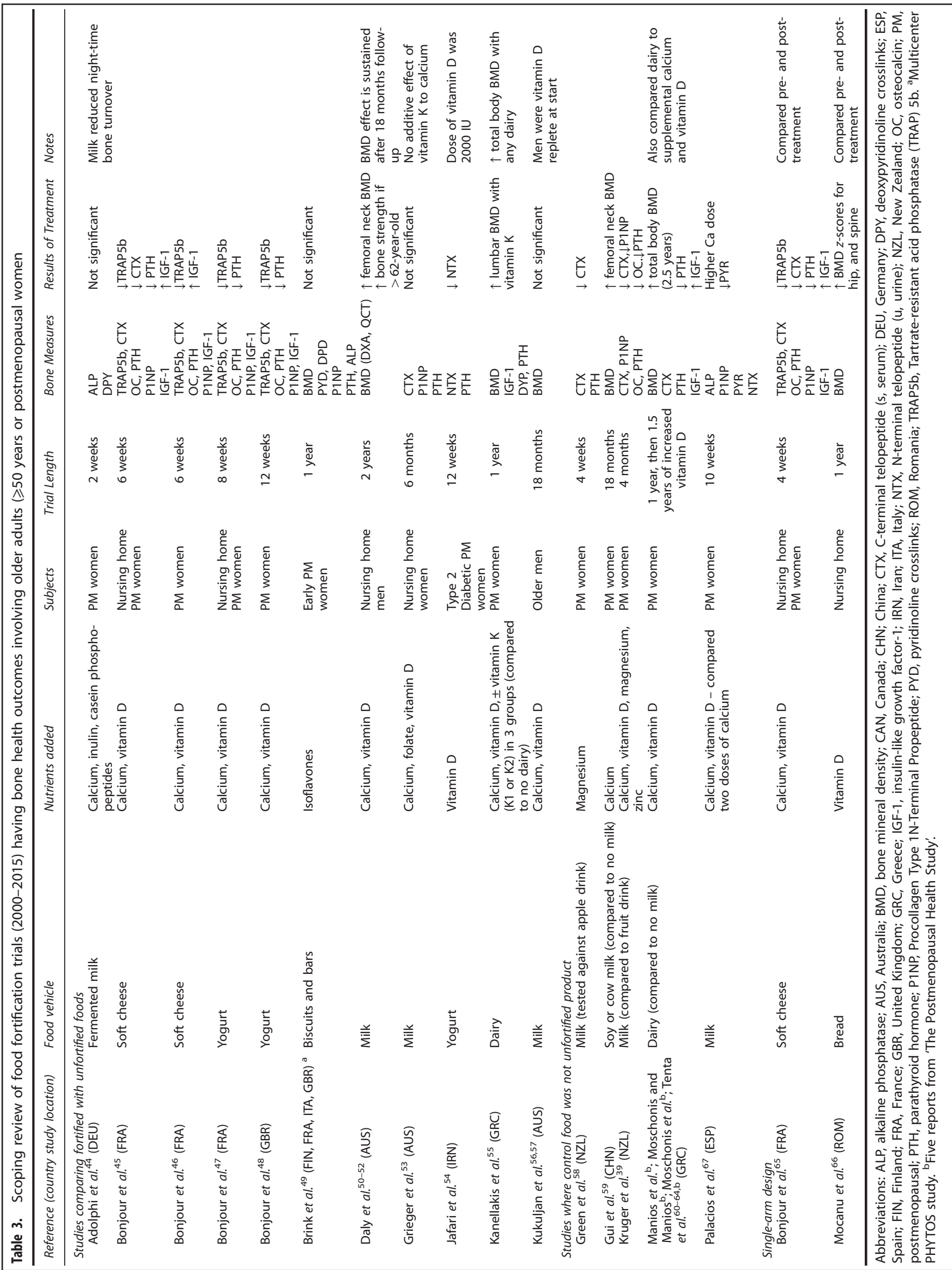




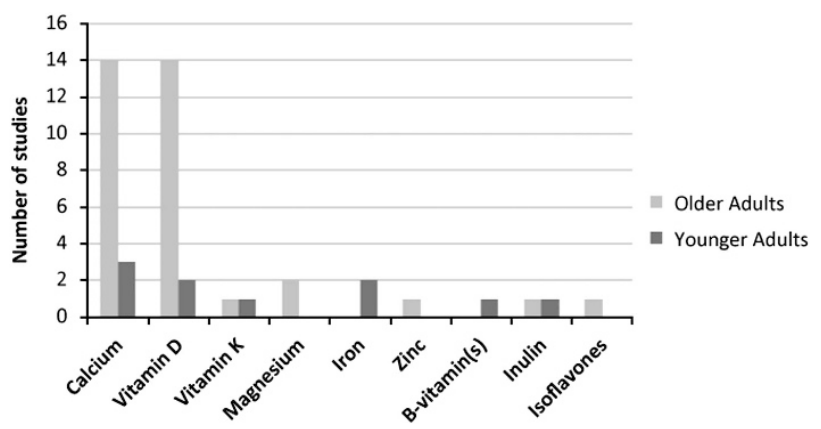

Figure 1. Nutrients added to foods and tested for bone effects: results of a scoping review from 1996 to 2015. Number of included studies distributed according to the added nutrients. Out of 360 articles, 24 studies, 6 and 18 in adults less than and $\geqslant 50$ years, respectively, met the predetermined following criteria: human study in adults $\geqslant 18$ years; original trial testing fortified foods over time, with specific bone outcomes measured pre- and post intervention.
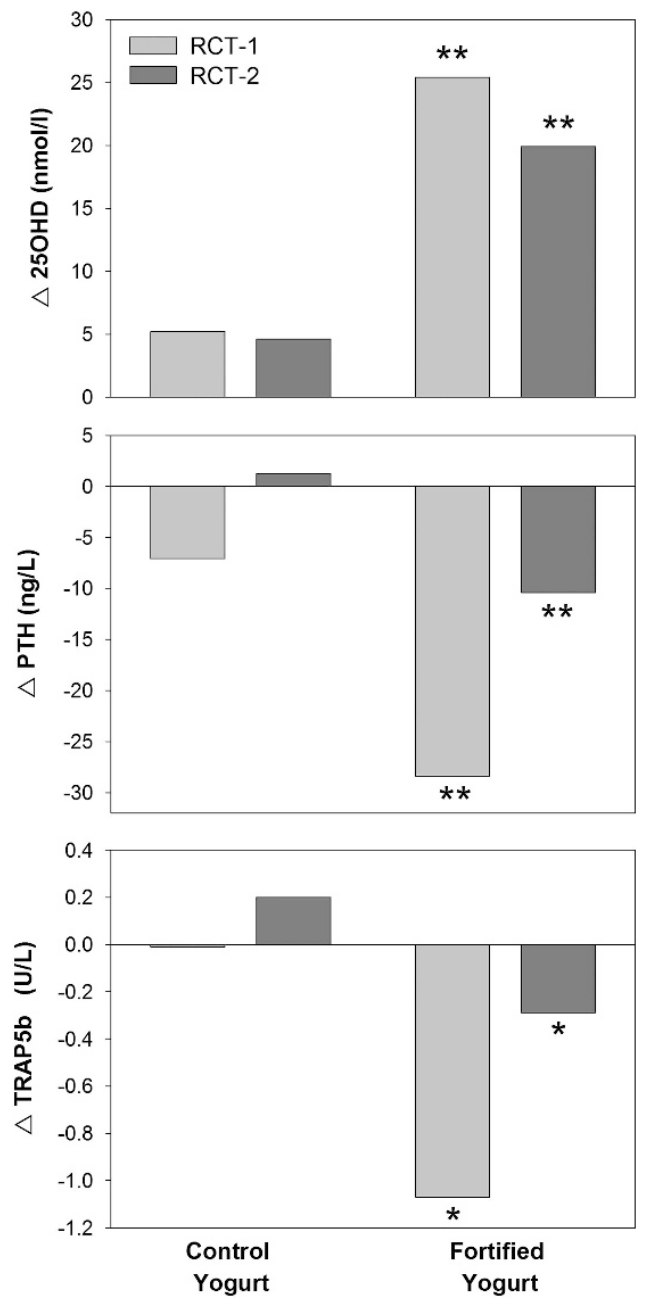

Figure 2. Changes $(\Delta)$ after 56 days (D56-D0) of consumption of non-fortified control or fortified yogurts in two independent double-blind randomized clinical trials. One trial (RCT-1) was carried out in women living in French (FR) nursing homes, the other (RCT-2) in women living in a Great Britain (GRB) community dwelling home. Columns represent the difference after $56 \mathrm{~d}$ in serum 25OHD (upper panel), PTH (middle panel) and TRAP5b (lower panel). Data are taken from two original studies published in $2013^{47}$ and $2015 .{ }^{48}$ In both trials, the differences in changes between fortified and control (nonfortified) yogurt groups were statistically significant for 25OHD, PTH and TRAP5b: ${ }^{* *} P<0.001 ;{ }^{*} P<0.0025$. increased risk of falls and fracture. ${ }^{84}$ Below these ULs, the evidence suggesting adverse cardiovascular effects of calcium supplementation is inconsistent. ${ }^{85}$ There is reasonable assurance that consumption of calcium and/or vitamin D-fortified foods should not result in adverse effects.

\section{SUMMARY}

In this scoping review, we analyzed 24 original studies in which fortified foods were evaluated for their potential beneficial effects on bone outcomes in adulthood. Calcium and vitamin D were the fortificants most often added, whereas milk and dairy-related products were the most frequently used fortified foods. Several studies rigorously compared calcium-vitamin D-fortified foods with unfortified food equivalents, in a double-blind randomized controlled design. Evidence was obtained that, in postmenopausal women and elderly, food fortification with calcium and vitamin D substantially improves vitamin D status, provides a greater prevention of secondary hyperparathyroidism and significantly reduces accelerated bone turnover. The pattern of these biochemical effects can be interpreted as beneficial to the global prevention of osteoporosis and fragility fractures with aging. However, further research is needed to examine the effects of adding more of the putative bone-healthy nutrients in one fortified food product.

\section{CONFLICT OF INTEREST}

J-PB is a clinical consultant for Yoplait, France. Ms Flore DONTOT, scientific collaborator of Yoplait, France, facilitated the administrative coordination of the authors. Yoplait, France, had no role in the design, analysis of the data discussed in this scoping review or writing the manuscript. The remaining authors declare no conflict of interest.

\section{ACKNOWLEDGEMENTS}

SWJ and J-PB were in charge of drafting the manuscript and designed the figures. WMK, MIK and MPW revised the first drafts. All authors critically reviewed the manuscript and approved the final version. J-PB took the responsibility of the final version.

\section{REFERENCES}

1 World Health Organization Prevention and management of osteoporosis. Report of a scientific group. WHO Technical Report Series 2003; No 921.

2 Heaney RP. Nutrition and risk for osteoprosis. In: Marcus M, Feldman D, Nelson DA, Rosen CJ (eds). Osteoporosis. Elsevier: Amsterdam, The Netherlands, 2008; pp 799-836.

3 Tucker KL. Osteoporosis prevention and nutrition. Curr Osteoporos Rep 2009; 7: 111-117.

4 Sahni S, Hannan MT, Blumberg J, Cupples LA, Kiel DP, Tucker KL. Inverse association of carotenoid intakes with 4-y change in bone mineral density in elderly men and women: the Framingham Osteoporosis Study. Am J Clin Nutr 2009; 89: 416-424.

5 Heaney RP. Dairy and bone health. J Am Coll Nutr 2009; 28 (Suppl 1): 82 S-90 S

6 Bischoff-Ferrari HA, Dawson-Hughes B, Baron JA, Kanis JA, Orav EJ, Staehelin HB et al. Milk intake and risk of hip fracture in men and women: a meta-analysis of prospective cohort studies. J Bone Miner Res 2011; 26: 833-839.

7 Sahni S, Tucker KL, Kiel DP, Quach L, Casey VA, Hannan MT. Milk and yogurt consumption are linked with higher bone mineral density but not with hip fracture: the Framingham Offspring Study. Arch Osteoporos 2013; 8: 119.

8 Sahni S, Mangano KM, Tucker KL, Kiel DP, Casey VA, Hannan MT. Protective association of milk intake on the risk of hip fracture: results from the Framingham Original Cohort. J Bone Miner Res 2014; 29: 1756-1762.

9 Radavelli-Bagatini S, Zhu K, Lewis JR, Prince RL. Dairy food intake, peripheral bone structure, and muscle mass in elderly ambulatory women. $J$ Bone Miner Res 2014; 29: 1691-1700.

10 Bonjour JP. Dietary protein: an essential nutrient for bone health. J Am Coll Nutr 2005; 24 (6 Suppl): 526S-536S. 
11 Chapuy MC, Arlot ME, Duboeuf F, Brun J, Crouzet B, Arnaud S et al. Vitamin D3 and calcium to prevent hip fractures in the elderly women. N Engl J Med 1992; 327: 1637-1642.

12 Reid IR, Ames RW, Evans MC, Gamble GD, Sharpe SJ. Effect of calcium supplementation on bone loss in postmenopausal women. $N$ Engl J Med 1993; 328: 460-464

13 Chevalley T, Rizzoli R, Nydegger V, Slosman D, Rapin $\mathrm{CH}$, Michel JP et al. Effects of calcium supplements on femoral bone mineral density and vertebral fracture rate in vitamin-D-replete elderly patients. Osteoporos Int 1994; 4: 245-252.

14 Dawson-Hughes B, Harris SS, Krall EA, Dallal GE. Effect of calcium and vitamin D supplementation on bone density in men and women 65 years of age or older. N Engl J Med 1997; 337: 670-676.

15 Zhu K, Devine A, Dick IM, Wilson SG, Prince RL. Effects of calcium and vitamin D supplementation on hip bone mineral density and calcium-related analytes in elderly ambulatory Australian women: a five-year randomized controlled trial. J Clin Endocrinol Metab 2008; 93: 743-749.

16 Bonjour JP, Gueguen L, Palacios C, Shearer MJ, Weaver CM. Minerals and vitamins in bone health: the potential value of dietary enhancement. Br J Nutr 2009; 101: 1581-1596.

17 Macdonald HM, Black AJ, Aucott L, Duthie G, Duthie S, Sandison R et al. Effect of potassium citrate supplementation or increased fruit and vegetable intake on bone metabolism in healthy postmenopausal women: a randomized controlled trial. Am J Clin Nutr 2008; 88: 465-474.

18 Fenton TR, Eliasziw M, Tough SC, Lyon AW, Brown JP, Hanley DA. Low urine pH and acid excretion do not predict bone fractures or the loss of bone mineral density: a prospective cohort study. BMC Musculoskelet Disord 2010; 11: 88

19 Frassetto LA, Hardcastle AC, Sebastian A, Aucott L, Fraser WD, Reid DM et al. No evidence that the skeletal non-response to potassium alkali supplements in healthy postmenopausal women depends on blood pressure or sodium chloride intake. Eur J Clin Nutr 2012; 66: 1315-1322.

20 Hanley DA, Whiting SJ. Does a high dietary Acid content cause bone loss, and can bone loss be prevented with an alkaline diet? J Clin Densitom 2013; 16: 420-425.

21 Bonjour JP. Nutritional disturbance in acid-base balance and osteoporosis: a hypothesis that disregards the essential homeostatic role of the kidney. Br J Nutr 2013; 110: 1168-1177.

22 Coxam V. Current data with inulin-type fructans and calcium, targeting bone health in adults. J Nutr 2007; 137(11 Suppl): 2527S-2533S.

23 Mangels AR. Bone nutrients for vegetarians. Am J Clin Nutr 2014; 100(Suppl 1): 469 S-475 S.

24 Zofkova I, Nemcikova P, Matucha P. Trace elements and bone health. Clin Chem Lab Med 2013; 51: 1555-1561.

25 Ruxton $\mathrm{CH}$, Derbyshire E, Toribio-Mateas M. Role of fatty acids and micronutrients in healthy ageing: a systematic review of randomised controlled trials set in the context of European dietary surveys of older adults. J Hum Nutr Diet 2015; e-pub head of print 18 August 2015; doi: 10.1111/jhn.12335.

26 Opinion on the substantiation of health claims related to vitamin $\mathrm{K}$ on maintenance of bone. EFSA Panel on Dietetic Products, Nutrition and Allergies (NDA). EFSA J 2009a; 7: 1228.

27 Opinion on the substantiation of health claims related to magnesium on maintenance of bone. EFSA Panel on Dietetic Products, Nutrition and Allergies (NDA). EFSA J 2009b; 7: 1216.

28 Opinion on the substantiation of health claims related to phophorus on maintenance of bone EFSA Panel on Dietetic Products, Nutrition and Allergies (NDA). EFSA J 2009c; 7: 1219.

29 Opinion on the substantiation of health claims related to manganese on maintenance of bone. EFSA Panel on Dietetic Products, Nutrition and Allergies (NDA). EFSA J 2009d; 7: 1217

30 Opinion on the substantiation of health claims related to zinc on maintenance of bone. EFSA Panel on Dietetic Products, Nutrition and Allergies (NDA). EFSA J 2009e; 7: 1229

31 World Health Organization Guidelines on food fortification with micronutrients, Publisher. World Health Organization: Geneva, Switzerland. Available at http:// www.who.int./nutrition/publications, 2006.

32 Ewen S, Vatanparast H. Current Mandatory Fortificants in Developed Nations Compared to Developing Nations. In: Preedy VR, Srirajaskanthan R, Patel VB (eds). Handbook of Food Fortification and Health: From Concepts to Public Health Applications. Springer Science+Business Media: New York, USA, 2013; vol. 1, pp 15-30.

33 Bailey RL, Gahche JJ, Lentino CV, Dwyer JT, Engel JS, Thomas PR et al. Dietary supplement use in the United States, 2003-2006. J Nutr 2011; 141: 261-266.

34 Vatanparast H, Calvo MS, Green TJ, Whiting SJ. Despite mandatory fortification of staple foods, vitamin D intakes of Canadian children and adults are inadequate. J Steroid Biochem Mol Biol 2010; 121: 301-303.
35 Marques-Vidal P, Pecoud A, Hayoz D, Paccaud F, Mooser V, Waeber G et al. Prevalence and characteristics of vitamin or dietary supplement users in Lausanne, Switzerland: the CoLaus study. Eur J Clin Nutr 2009; 63: 273-281.

36 Rovira MA, Grau M, Castaner O, Covas MI, Schroder H. REGICOR Investigators Dietary supplement use and health-related behaviors in a Mediterranean population. J Nutr Educ Behav 2013; 45: 386-391.

37 Grant MJ, Booth A. A typology of reviews: an analysis of 14 review types and associated methodologies. Health Info Libr J 2009; 26: 91-108.

38 Ferrar L, van der Hee RM, Berry M, Watson C, Miret S, Wilkinson J et al. Effects of calcium-fortified ice cream on markers of bone health. Osteoporos Int 2011; 22: 2721-2731.

39 Kruger MC, Booth CL, Coad J, Schollum LM, Kuhn-Sherlock B, Shearer MJ. Effect of calcium fortified milk supplementation with or without vitamin $\mathrm{K}$ on biochemical markers of bone turnover in premenopausal women. Nutrition 2006; 22: $1120-1128$.

40 Toxqui L, Perez-Granados AM, Blanco-Rojo R, Wright l, de la Piedra C, Vaquero MP. Low iron status as a factor of increased bone resorption and effects of an iron and vitamin D-fortified skimmed milk on bone remodelling in young Spanish women. Eur J Nutr 2014; 53: 441-448.

41 Dahl WJ, Whiting SJ, Isaac TM, Weeks SJ, Arnold CJ. Effects of thickened beverages fortified with inulin on beverage acceptance, gastrointestinal function, and bone resorption in institutionalized adults. Nutrition 2005; 21: 308-311.

42 Blanco-Rojo R, Perez-Granados AM, Toxqui L, Zazo P, de la Piedra C, Vaquero MP. Relationship between vitamin $D$ deficiency, bone remodelling and iron status in iron-deficient young women consuming an iron-fortified food. Eur J Nutr 2013; 52: 695-703.

43 Tapola NS, Karvonen HM, Niskanen LK, Sarkkinen ES. Mineral water fortified with folic acid, vitamins B6, B12, D and calcium improves folate status and decreases plasma homocysteine concentration in men and women. Eur J Clin Nutr 2004; 58: 376-385.

44 Adolphi B, Scholz-Ahrens KE, de Vrese M, Acil Y, Laue C, Schrezenmeir J. Short-term effect of bedtime consumption of fermented milk supplemented with calcium, inulin-type fructans and caseinphosphopeptides on bone metabolism in healthy, postmenopausal women. Eur J Nutr 2009; 48: 45-53.

45 Bonjour JP, Benoit V, Pourchaire O, Rousseau B, Souberbielle JC. Nutritional approach for inhibiting bone resorption in institutionalized elderly women with vitamin D insufficiency and high prevalence of fracture. J Nutr Health Aging 2011; 15: 404-409.

46 Bonjour JP, Benoit V, Rousseau B, Souberbielle JC. Consumption of Vitamin D-and Calcium-Fortified Soft White Cheese Lowers the Biochemical Marker of Bone Resorption TRAP 5b in Postmenopausal Women at Moderate Risk of Osteoporosis Fracture. J Nutr 2012; 142: 698-703.

47 Bonjour JP, Benoit V, Payen F, Kraenzlin M. Consumption of yogurts fortified in vitamin $\mathrm{d}$ and calcium reduces serum parathyroid hormone and markers of bone resorption: a double-blind randomized controlled trial in institutionalized elderly women. J Clin Endocrinol Metab 2013; 98: 2915-2921.

48 Bonjour J-P, Benoit V, Atkin S, Walrand S. Fortification of yogurts with vitamin D and calcium enhances the inhibition of serum parathyroid hormone and bone resorption markers: a double-blind randomized controlled trial in women over 60 living in a community dwelleing home. J Nutr Health Aging 2015; 19: 500-507

49 Brink E, Coxam V, Robins S, Wahala K, Cassidy A, Branca F et al. Long-term consumption of isoflavone-enriched foods does not affect bone mineral density, bone metabolism, or hormonal status in early postmenopausal women: a randomized, double-blind, placebo controlled study. Am J Clin Nutr 2008; 87: 761-770.

50 Daly RM, Bass S, Nowson C. Long-term effects of calcium-vitamin-D3-fortified milk on bone geometry and strength in older men. Bone 2006; 39: 946-953.

51 Daly RM, Brown M, Bass S, Kukuljan S, Nowson C. Calcium- and vitamin D3-fortified milk reduces bone loss at clinically relevant skeletal sites in older men: a 2-year randomized controlled trial. J Bone Miner Res 2006; 21: 397-405.

52 Daly RM, Petrass N, Bass S, Nowson CA. The skeletal benefits of calcium- and vitamin D3-fortified milk are sustained in older men after withdrawal of supplementation: an 18-mo follow-up study. Am J Clin Nutr 2008; 87: 771-777.

53 Grieger JA, Nowson CA. Use of calcium, folate, and vitamin D(3)-fortified milk for 6 months improves nutritional status but not bone mass or turnover, in a group of Australian aged care residents. J Nutr Elder 2009; 28: 236-254.

54 Jafari T, Faghihimani E, Feizi A, Iraj B, Javanmard SH, Esmaillzadeh A et al. Effects of vitamin D-fortified low fat yogurt on glycemic status, anthropometric indexes, inflammation, and bone turnover in diabetic postmenopausal women: a randomised controlled clinical trial. Clin Nutr 2015; 35: 67-76.

55 Kanellakis S, Moschonis G, Tenta R, Schaafsma A, van den Heuvel EG, Papaioannou $\mathrm{N}$ et al. Changes in parameters of bone metabolism in postmenopausal women following a 12-month intervention period using dairy products enriched with calcium, vitamin $\mathrm{D}$, and phylloquinone (vitamin $\mathrm{K}(1)$ ) or 
menaquinone-7 (vitamin K (2)): the Postmenopausal Health Study II. Calcif Tissue Int 2012; 90: 251-262.

56 Kukuljan S, Nowson CA, Bass SL, Sanders K, Nicholson GC, Seibel MJ et al. Effects of a multi-component exercise program and calcium-vitamin-D3-fortified milk on bone mineral density in older men: a randomised controlled trial. Osteoporos Int 2009; 20: 1241-1251.

57 Kukuljan S, Nowson CA, Sanders KM, Nicholson GC, Seibel MJ, Salmon J et al. Independent and combined effects of calcium-vitamin D3 and exercise on bone structure and strength in older men: an 18-month factorial design randomized controlled trial. J Clin Endocrinol Metab 2011; 96: 955-963.

58 Green JH, Booth C, Bunning R. Impact of supplementary high calcium milk with additional magnesium on parathyroid hormone and biochemical markers of bone turnover in postmenopausal women. Asia Pac J Clin Nutr 2002; 11: 268-273.

59 Gui JC, Brasic JR, Liu XD, Gong GY, Zhang GM, Liu CJ et al. Bone mineral density in postmenopausal Chinese women treated with calcium fortification in soymilk and cow's milk. Osteoporos Int 2012; 23: 1563-1570.

60 Manios Y, Moschonis G, Trovas G, Lyritis GP. Changes in biochemical indexes of bone metabolism and bone mineral density after a 12-mo dietary intervention program: The Postmenopausal Health Study. Am J Clin Nutr 2007; 86: 781-789.

61 Manios Y, Moschonis G, Panagiotakos DB, Farajian P, Trovas G, Lyritis GP. Changes in biochemical indices of bone metabolism in post-menopausal women following a dietary intervention with fortified dairy products. J Hum Nutr Diet 2009; 22: 156-165.

62 Moschonis G, Manios Y. Skeletal site-dependent response of bone mineral density and quantitative ultrasound parameters following a 12-month dietary intervention using dairy products fortified with calcium and vitamin D: The Postmenopausal Health Study. Br J Nutr 2006; 96: 1140-1148.

63 Moschonis G, Katsaroli I, Lyritis GP, Manios Y. The effects of a 30-month dietary intervention on bone mineral density: the Postmenopausal Health Study. Br J Nutr 2010; 104: 100-107.

64 Tenta R, Moschonis G, Koutsilieris M, Manios Y. Calcium and vitamin D supplementation through fortified dairy products counterbalances seasonal variations of bone metabolism indices: the Postmenopausal Health Study. Eur J Nutr 2011; 50: 341-349.

65 Bonjour JP, Benoit V, Pourchaire O, Ferry M, Rousseau B, Souberbielle JC. Inhibition of markers of bone resorption by consumption of vitamin $D$ and calcium-fortified soft plain cheese by institutionalised elderly women. Br J Nutr 2009; 102: 962-966.

66 Mocanu V, Stitt PA, Costan AR, Voroniuc O, Zbranca E, Luca V et al. Long-term effects of giving nursing home residents bread fortified with 125 microg (5000 IU) vitamin D(3) per daily serving. Am J Clin Nutr 2009; 89: 1132-1137.

67 Palacios S, Castelo-Branco C, Cifuentes I, von Helde S, Baro L, Tapia-Ruano C et al. Changes in bone turnover markers after calcium-enriched milk supplementation in healthy postmenopausal women: a randomized, double-blind, prospective clinical trial. Menopause 2005; 12: 63-68.

68 Bonjour JP, Kraenzlin M, Levasseur R, Warren M, Whiting S. Dairy in adulthood: from foods to nutrient interactions on bone and skeletal muscle health. J Am Coll Nutr 2013; 32: 251-263.

69 Martin AD, Apports nutritionnels conseillés pour la population française, 3ème édition TEC\&DOC, Paris 2001.

70 Ross AC, Manson JE, Abrams SA, Aloia JF, Brannon PM, Clinton SK et al. The 2011 report on dietary reference intakes for calcium and vitamin D from the
Institute of Medicine: what clinicians need to know. J Clin Endocrinol Metab 2011; 96: $53-58$.

71 Lutter CK, Dewey KG. Proposed nutrient composition for fortified complementary foods. J Nutr 2003; 133: 3011S-3020S.

72 Schanler RJ, Garza C. Improved mineral balance in very low birth weight infants fed fortified human milk. J Pediatr 1988; 112: 452-456.

73 Bonjour JP, Kohrt W, Levasseur R, Warren M, Whiting S, Kraenzlin M. Biochemical markers for assessment of calcium economy and bone metabolism: application in clinical trials from pharmaceutical agents to nutritional products. Nutr Res Rev 2014; 27: 252-267.

74 Hjortebjerg R, Frystyk J. Determination of IGFs and their binding proteins. Best Pract Res Clin Endocrinol Metab 2013; 27: 771-781.

75 Jüppner H, Fulehan GE-H. Measurement of Parathyroid Hormone. In: Seibel M, Robins SP, Bilezikian JP (eds). Dynamics of Bone and Cartilage Metabolism: Principles and Clinical Applications, 2nd edn. Academic Press: San Diego, CA, USA, 2006; pp 507-512.

76 Kraenzlin ME, Seibel MJ. Measurements of Biochemical Markers of Bone Resorption. In: Seibel MJ, Robins SP, Bilezikian JP (eds). Dynamic Bone and Cartilage Metabolism: Principles and Clinical Applications. 2nd edn, Academic Press: San Diego, CA, USA, 2006; pp 541-563.

77 Naylor K, Eastell R. Bone turnover markers: use in osteoporosis. Nat Rev Rheumatol 2012; 8: 379-389.

78 Vasikaran S, Cooper C, Eastell R, Griesmacher A, Morris HA, Trenti T et al. International osteoporosis foundation and international federation of clinical chemistry and laboratory medicine position on bone marker standards in osteoporosis. Clin Chem Lab Med 2011; 49: 1271-1274.

79 Garnero P, Sornay-Rendu E, Duboeuf F, Delmas P. Markers of bone turnover predict postmenopausal forearm bone loss over 4 years: the OFELY study. J Bone Miner Res 1999; 14: 1614-1621.

80 Gerdhem P, Ivaska KK, Alatalo SL, Halleen JM, Hellman J, Isaksson A et al. Biochemical markers of bone metabolism and prediction of fracture in elderly women. J Bone Miner Res 2004; 19: 386-393.

81 Johnell O, Oden A, De Laet C, Garnero P, Delmas PD, Kanis JA. Biochemical indices of bone turnover and the assessment of fracture probability. Osteoporos Int 2002; 13: $523-526$.

82 Heaney RP. Is the paradigm shifting? Bone 2003; 33: 457-465.

83 Dwyer JT, Wiemer KL, Dary O, Keen CL, King JC, Miller KB et al. Fortification and health: challenges and opportunities. Adv Nutr 2015; 6: 124-131.

84 Sanders KM, Stuart AL, Williamson EJ, Simpson JA, Kotowicz MA, Young D et al. Annual high-dose oral vitamin $D$ and falls and fractures in older women: a randomized controlled trial. JAMA 2010; 303: 1815-1822.

85 Bauer DC. Clinical practice. Calcium supplements and fracture prevention. N Engl J Med 2013; 369: 1537-1543.

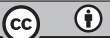

This work is licensed under a Creative Commons Attribution 4.0 International License. The images or other third party material in this article are included in the article's Creative Commons license, unless indicated otherwise in the credit line; if the material is not included under the Creative Commons license, users will need to obtain permission from the license holder to reproduce the material. To view a copy of this license, visit http://creativecommons.org/licenses/ by/4.0/ 